\title{
Effects of triptolide on RIZ1 expression, proliferation, and apoptosis in multiple myeloma U266 cells
}

\author{
Fei ZHAO ${ }^{1, \#}$, Yan CHEN ${ }^{1, \#}$, Ling-lan ZENG ${ }^{1}$, Rui $\mathrm{LI}^{2}$, Rong ZENG ${ }^{1}, \mathrm{Lu} \mathrm{WEN}^{1}$, Yuan $\mathrm{LIU}^{1}$, Chun ZHANG ${ }^{1, *}$ \\ ${ }^{1}$ Department of Hematology, Union Hospital, Tongji Medical College, Huazhong University of Science and Technology, Wuhan 430022, \\ China; ${ }^{2}$ Department of Hematology, Affiliated Kunhua Hospital of Kunming Medical College, the First People's Hospital of Yunnan Pro- \\ vince, Kunming 650032, China
}

\begin{abstract}
Aim: To investigate the effects of triptolide on proliferation and apoptosis as well as on the expression of RIZ1 in the human multiple myeloma cell line U266 in vitro.

Methods: The effect of triptolide on the growth of U266 cells was studied by MTT assay. Apoptosis was detected by Hoechst 33258 staining and Annexin V/PI double-labeled flow cytometry, and caspase-3 mRNA was measured by RT-PCR. Western blotting, flow cytometry and RT-PCR were used to assess the expression of RIZ1, and the location and expression of H3K9me1 were detected by confocal microscopy and Western blotting.

Results: Triptolide significantly inhibited the proliferation of U266 cells in a time- and concentration-dependent manner (the IC ${ }_{50}$ value for a $24-\mathrm{h}$ exposure was $157.19 \pm 0.38 \mathrm{nmol} / \mathrm{L})$. Triptolide induced typical apoptotic morphological changes. Triptolide 40, 80, and 160 $\mathrm{nmol} / \mathrm{L}$ treatment induced significant caspase-3-dependent apoptosis compared with control group $(10.5 \% \pm 1.23 \%, 37.9 \% \pm 2.45 \%$, and $40.5 \% \pm 2.30 \%$ vs $3.8 \% \pm 1.98 \%, P<0.05$ ). Compared with peripheral blood monocular cells (PBMC) from healthy donors, the protein expression of RIZ1 in U266 cells was relatively low, but the mRNA and protein expression of RIZ1 were strikingly increased by triptolide in a concentration-dependent manner. Triptolide increased the protein expression of RIZ1 and RIZ1 methylates histone H3 lysine 9 in U266 cells.
\end{abstract}

Conclusion: Triptolide increased the protein expression of RIZ1, inhibited the proliferation, and induced caspase-dependent apoptosis in U266 cells.

Keywords: triptolide; multiple myeloma; proliferation; apoptosis; RIZ1; RIZ1 methylates histone H3 lysine 9; caspase 3

Acta Pharmacologica Sinica (2010) 31: 733-740; doi: 10.1038/aps.2010.49

\section{Introduction}

Multiple myeloma (MM), a type of malignant plasma cell dyscrasia originating from $B$ lymphocytes, produces abundant monoclonal immunoglobulins. These neoplastic plasma cells are believed to arise from a post-germinal center B cell that migrates to the bone marrow, adheres to the marrow stroma and triggers subsequent bone resorption and a paracrine cytokine loop ${ }^{[1]}$. The natural course of the disease may progress through monoclonal gammopathy of undetermined significance (MGUS), smoldering myeloma, intramedullary myeloma and finally, extramedullary myeloma. Multiple myeloma is still an incurable disease. Although conventional cytotoxic chemotherapy prolongs survival in symptomatic patients, the prognosis of these patients remains poor ${ }^{[2]}$. After

\footnotetext{
\# The first two authors contributed equally to this work.

* To whom correspondence should be addressed.

E-mail zhangchun23@yahoo.com.cn

Received 2009-10-29 Accepted 2010-03-29
}

treatment with conventional cytotoxic agents ${ }^{[3]}$, relapses still inevitably occur, indicating the need for continued investigation of novel agents to treat this disease.

Triptolide, a tri-epoxide phenanthrene and a major component of the Chinese herb Tripterygium wilfordii Hook F (TWHF), has multiple biological effects resulting from its immunosuppressive, anti-inflammatory ${ }^{[4,5]}$ and anti-tumor properties $^{[6]}$. In diverse hematological tumors, triptolide shows anti-tumor activity, and many studies have been carried out to elucidate the potential anti-tumor mechanisms ${ }^{[7-9]}$. Previous studies suggested that triptolide induces apoptosis of multiple myeloma through the upstream signaling pathway of PI3k/Akt/NF-kB and is associated with the MAPK pathway via mitochondrial apoptotic signaling as well as caspase and Bcl-2 family members ${ }^{[10]}$. The mechanism responsible for its effects on multiple myeloma, however, is still unclear.

The retinoblastoma protein-interacting zinc-finger (RIZ) gene, located on 1p36, is a recently described tumor suppressor gene and a member of the protein methyltransferase superfam- 
ily ${ }^{[11]}$. The RIZ gene encodes two proteins, RIZ1 and RIZ2. While RIZ1 contains the PR domain, RIZ2 does not. RIZ gene expression is altered in a variety of human cancers and is now considered to be a candidate tumor suppressor ${ }^{[12]}$. RIZ1 methylates histone $\mathrm{H} 3$ lysine 9 (H3K9), a modification that is important for transcriptional repression ${ }^{[13]}$. RIZ1 expression and activity are reduced in many cancers such as hepatocellular carcinoma ${ }^{[14]}$ and epithelial ovarian carcinoma ${ }^{[15]}$. In AML cell lines and patient samples, RIZ1 expression is reduced relative to normal bone marrow. In addition, the RIZ1 knockout mouse has a high incidence of diffuse large B-cell lymphoma ${ }^{[11]}$. In chronic myelogenous leukemia (CML), blastic transformation is associated with the loss of heterozygosity in the chromosomal region containing RIZ1 $1^{[16]}$. All of the above data suggest that there is a close connection between RIZ1 and hematologic malignancies, but there have been no studies regarding this in MM. The aim of our research was to investigate the relationship between RIZ1 and multiple myeloma, as well as the effects of triptolide on RIZ1 expression, cell proliferation and apoptosis in multiple myeloma.

\section{Materials and methods}

\section{Cell line and reagents}

The MM cell line U266 was obtained from ATCC (Rockville, USA), and peripheral blood monocular cells (PBMC) were obtained by Ficoll-Hypaque density gradient centrifugation of blood collected from healthy donors. All cell types were cultured in RPMI-1640 (GibcoBRL, USA) containing 10\% fetal bovine serum (Sijiqing Co Ltd, Hangzhou, China) and incubated in $5 \% \mathrm{CO}_{2}$ at $37^{\circ} \mathrm{C}$. Triptolide with $98 \%$ purity was purchased from Sigma (St Louis, MO, USA), initially dissolved in dimethylsulfoxide (DMSO), stored at $-20^{\circ} \mathrm{C}$, and then thawed before use. 3-(4,5-Dimethyl-2-thiazolyl)-2,5-diphenyl-2Htetrazolium (MTT), DMSO and Hoechst 33258 were purchased from Sigma. RNA Trizol was purchased from Invitrogen (CA, USA). A reverse transcription (RT)-polymerase chain reaction (PCR) kit was purchased from TOYOBO (Japan). The monoclonal antibody against monomethyl histone $\mathrm{H} 3$ lysine 9 (H3K9me1) was purchased from Upstate Biotechnology (Charlottesville, VA, USA), and the monoclonal antibody against RIZ1 was purchased from Santa Cruz (California, USA). Tetrametrylrhodarnine isothiocyante (TRITC)-labeled secondary antibodies, fluorescein isothiocyanate (FITC)-labeled secondary antibodies, horseradish peroxidase (HRP)-labeled secondary antibodies and chemiluminescence (ECL) reagent kits were purchased from Pierce Biotechnology (Rockford, IL, USA).

\section{Growth inhibition assay}

The antiproliferative effect of triptolide on U266 cells was determined using the MTT dye uptake method. In brief, the cells (50000 per well) were incubated in quintuplicate in 96-well plates. Triptolide was added, with a final concentration of $40,50,60,80,90$, and $100 \mathrm{nmol} / \mathrm{L}$, and the cells were treated for 24,36 , and $72 \mathrm{~h}$. Thereafter, $20 \mu \mathrm{L}$ MTT $(5 \mathrm{mg} / \mathrm{mL}$ in phosphate-buffered saline) was added to each well. After
$4 \mathrm{~h}$ at $37^{\circ} \mathrm{C}$, the supernatant was removed, and $150 \mu \mathrm{L}$ DMSO was added. When the blue crystal was dissolved, the optical density $(O D)$ was detected at a $570-\mathrm{nm}$ wavelength using a 96-well multiscanner autoreader (Bio-Rad M450, USA), with $630 \mathrm{~nm}$ used as the reference wavelength. The following formula was used: cell proliferation inhibited $(\%)=[1-(O D$ of the experimental samples/OD of the control) $] \times 100$. The $\mathrm{IC}_{50}$ was the concentration that caused a $50 \%$ inhibition of cell proliferation.

\section{Flow cytometry analysis for apoptosis quantification}

Apoptosis was measured by Annexin V-FITC/PI double staining using the kit from Bender MedSystems Inc (Burlingame, CA) and fluorescence-activated cell sorter (FACS) analysis (FacsScan; BD Biosciences). Briefly, cells were treated with 0, 40,80 , and $160 \mathrm{nmol} / \mathrm{L}$ of triptolide, and the cells were harvested at $24 \mathrm{~h}$. After incubation, $100 \mu \mathrm{L}$ of treated cells was transferred to a 5-mL culture tube, and a solution containing $5 \mu \mathrm{L}$ Annexin V-FITC plus $10 \mu \mathrm{L}$ PI was added. The tube was gently vortexed and incubated for $15 \mathrm{~min}$ at room temperature in the dark. Afterwards, $300 \mu \mathrm{L}$ binding buffer was added, and the cells were analyzed immediately by flow cytometry. The extent of early apoptosis was determined as the percentage of Annexin $\mathrm{V}^{+} / \mathrm{PI}^{-}$cells. Flow cytometric analysis was performed with a FACSCaliber using CellQuest software (BD, San Diego, CA, USA).

\section{Hoechst 33258 staining}

Nuclear fragmentation was visualized by Hoechst 33258 staining of apoptotic nuclei. Apoptotic cells were collected by centrifugation, washed with phosphate-buffered saline (PBS), and fixed in $4 \%$ paraformaldehyde for $20 \mathrm{~min}$ at room temperature. Subsequently, the cells were washed and resuspended in $20 \mu \mathrm{L}$ PBS before being deposited on polylysine-coated coverslips. The cells were then left to adhere to the cover slips for $30 \mathrm{~min}$ at room temperature, after which the cover slips were washed twice with PBS. The adhered cells were incubated with $0.1 \%$ Triton X-100 for 5 min at room temperature and rinsed with PBS three times. Cells were then treated with Hoechst 33258 for $30 \mathrm{~min}$ at $37^{\circ} \mathrm{C}$, rinsed with PBS and mounted on slides with glycerol-PBS. The cells were viewed with an Olympus fluorescence microscope (Japan).

\section{Western blotting}

Approximately $5 \times 10^{6}$ cells were plated and incubated for $24 \mathrm{~h}$ prior to the addition of triptolide. U266 cells were collected following a 48-h incubation with triptolide $(0,40,80$, and 160 $\mathrm{nmol} / \mathrm{L}$, respectively), and PBMC from healthy donors were collected and cultured for $48 \mathrm{~h}$. The cells were washed once with PBS, centrifuged, resuspended in a lysis buffer consisting of $50 \mathrm{mmol} / \mathrm{L}$ Tris (pH 7.4), $150 \mathrm{mmol} / \mathrm{L} \mathrm{NaCl}, 1 \%$ Triton X-100, $1 \%$ sodium deoxycholate, $0.1 \%$ sodium dodecylsulfate (SDS), $1 \mathrm{mmol} / \mathrm{L}$ phenylmethylsulphonyl fluoride, and protease inhibitors and incubated for $1 \mathrm{~h}$ at $4{ }^{\circ} \mathrm{C}$. Next, the cellular debris was pelleted by centrifugation at 15000 round per min for $30 \mathrm{~min}$, and the supernatant was collected. A BCA protein 
assay kit from Pierce Biotechnology was used to determine the protein concentration. Samples were separated on $8 \%-12 \%$ SDS-polyacrylamide gels and then transferred to nitrocellulose membranes using standard electroblotting procedures. After being blocked with 5\% skim milk in Tris-buffered saline with $0.1 \%$ Tween-20 (TBS-T), membranes were incubated with the primary antibodies anti-H3K9me1 (1:2000; Upstate Biotechnology, Charlottesville, VA, USA), anti-RIZ1 (1:200; Santa Cruz, California, USA) and anti- $\beta$-actin (1:1000; Santa Cruz, California, USA) at $4{ }^{\circ} \mathrm{C}$ overnight. Immunoblots were washed and then incubated with HRP-conjugated secondary antibodies (1:3000; Pierce Biotechnology, Rockford, IL, USA) for $1 \mathrm{~h}$ at room temperature and subsequently processed for enhanced chemiluminescence (ECL) detection using SuperSignal Substrate. Signals were detected by a chemiluminescence detection system (Bio-Rad, USA).

\section{Immunofluorescence with confocal microscopy}

After incubation with $40 \mu \mathrm{mol} / \mathrm{L}$ triptolide for $24 \mathrm{~h}$, cells were collected and fixed in $4 \%$ paraformaldehyde for $10 \mathrm{~min}$. The suspensions were permeabilized with $0.25 \%$ Triton X-100 for $10 \mathrm{~min}$, blocked with $3 \%$ bovine serum albumin for $30 \mathrm{~min}$ and then incubated with primary antibody against H3K9me1 (diluted 1:100; Upstate Biotechnology) overnight at $4^{\circ} \mathrm{C}$. Then, the samples were exposed to TRITC-labeled secondary antibody (diluted 1:100) for $1 \mathrm{~h}$ and stained with Hoechst 33258 $(10 \mu \mathrm{g} / \mathrm{mL})$ to visualize the DNA. Images were captured using an FV-500 confocal microscope (Olympus, Japan).

\section{RIZ1 protein analysis using flow cytometry}

Flow cytometry was performed to determine the expression of RIZ1 in U266 cells. A total of $1 \times 10^{6}$ cells were collected and washed after $48 \mathrm{~h}$ culture, anti-RIZ1 antibody (dilution 1:100; Santa Cruz) was added, and the mixture was kept at $4{ }^{\circ} \mathrm{C}$ overnight. Cells treated without primary antibody served as the negative control group. FITC-labeled secondary antibody (diluted 1:100) was applied for $30 \mathrm{~min}$ at room temperature. Stained cells were analyzed on a flow cytometer. The mean fluorescence intensity (MFI) of the cells was determined by the CellQuest software program. The final MFI was calculated by subtracting the MFI of the negative controls.

\section{Reverse transcription-polymerase chain reaction}

Total cellular RNA was extracted using Trizol reagent. Reverse transcription (RT)-polymerase chain reaction (PCR) was performed with the appropriate primers, following the protocol of the TOYOBO kit. A $20-\mu \mathrm{L}$ PCR reaction mixture was initially amplified. Primer pairs were all designed from human cDNA sequences available in GenBank and synthesized by Shanghai Bioengineering Company (Shanghai, China). The primer sequences and the predicted product size for RIZ1 and $\beta$-actin expression analyses were as follows. For RIZ1, the forward primer was 5'-CACAGGGCAGCGTTGGTC-3', and the reverse primer was 5'-GGCTAGGATCCTGCGTGGTT-3' (product size: $236 \mathrm{bp}$ ). The PCR was carried out using an initial denaturation of $94^{\circ} \mathrm{C}$ for $5 \mathrm{~min}$, followed by 34 cycles of $94^{\circ} \mathrm{C}$ for $30 \mathrm{~s}, 55.8^{\circ} \mathrm{C}$ for $30 \mathrm{~s}$, then $72^{\circ} \mathrm{C}$ for $30 \mathrm{~s}$, and a final extension of $72{ }^{\circ} \mathrm{C}$ for $7 \mathrm{~min}$. For caspase-3, the forward primer was 5'-TCAGAGGGGATCGTTGTAG-3', and the reverse primer was 5'-AGCTTGTCGGCATACTGTT-3' (product size: $262 \mathrm{bp}$ ). The PCR was carried out with an initial denaturation of $94^{\circ} \mathrm{C}$ for $5 \mathrm{~min}$, followed by 34 cycles of $94^{\circ} \mathrm{C}$ for $30 \mathrm{~s}, 53.6^{\circ} \mathrm{C}$ for $30 \mathrm{~s}$, then $72^{\circ} \mathrm{C}$ for $30 \mathrm{~s}$, and a final extension of $72^{\circ} \mathrm{C}$ for $7 \mathrm{~min}$. For $\beta$-actin, the forward primer was 5'-GAGCTACGAGCTGCCTGACG-3', and the reverse primer was 5'-CCTAGAAGCATTTGCGGTGG-3' (product size: 416 $\mathrm{bp})$. The PCR was carried out with an initial denaturation at $94^{\circ} \mathrm{C}$ for $5 \mathrm{~min}$, followed by 34 cycles of $94^{\circ} \mathrm{C}$ for $30 \mathrm{~s}, 60^{\circ} \mathrm{C}$ for $30 \mathrm{~s}$, then $72{ }^{\circ} \mathrm{C}$ for $30 \mathrm{~s}$, and a final extension at $72^{\circ} \mathrm{C}$ for $7 \mathrm{~min}$. The amplified PCR products were separated by electrophoresis on a $2 \%$ agarose gel and quantified according to the relative intensities of the bands compared to those of $\beta$-actin using the Smart View Bio-Electrophoresis Image Analysis System (Furi, Shanghai, China).

\section{Statistical analysis}

Results are expressed as mean \pm SD. The Student's $t$-test was used to compare quantitative data populations with normal distributions and equal variances. A value of $P<0.05$ was considered statistically significant.

\section{Results}

\section{Triptolide suppressed the growth of U266 cells in vitro}

The cytotoxicity of triptolide to U266 cells was calculated from the loss of cell viability using the MTT assay. U266 cells were treated with various concentrations of triptolide for $0,24,48$, and $72 \mathrm{~h}$. This treatment resulted in a significant decrease in the cell viability of U266 cells in a concentration- and timedependent manner (Figure 1). The $\mathrm{IC}_{50}$ value for the 24-h treatment was $157.19 \pm 0.38 \mathrm{nmol} / \mathrm{L}$. The $\mathrm{IC}_{50}$ values decreased gradually as the exposure time increased.

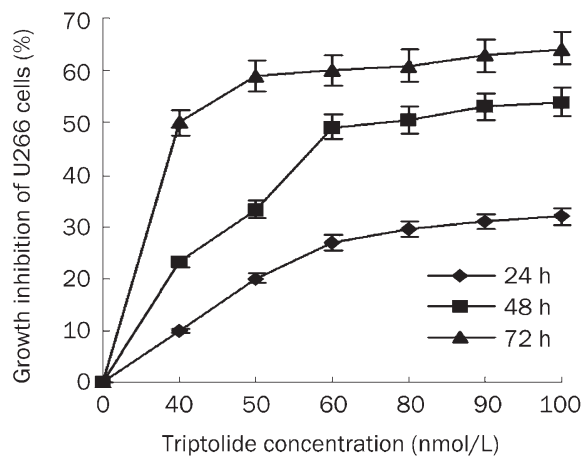

Figure 1. Dose- and time-dependent growth inhibition of U266 cells by triptolide. Data represent means $\pm S D$ of three independent experiments.

\section{Triptolide induced apoptosis in U266 cells}

Hoechst 33258 staining was used to investigate the change in the cell nuclei (Figure 2). Apoptotic bodies containing nuclear fragments were found in the triptolide-treated cells; in these 

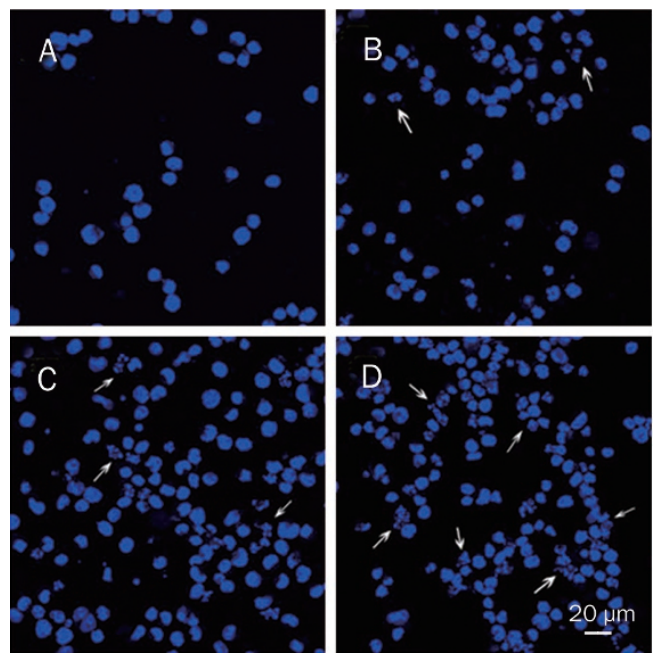

Figure 2. Triptolide-induced morphological changes of U266 cells stained with Hoechst $33258 \times 400$. (A) Untreated U266 cells. (B) Cells treated with $40 \mathrm{nmol} / \mathrm{L}$ triptolide for $24 \mathrm{~h}$. (C) Cells treated with $80 \mathrm{nmol} / \mathrm{L}$ triptolide for $24 \mathrm{~h}$. (D) Cells treated with $160 \mathrm{nmol} / \mathrm{L}$ triptolide for $24 \mathrm{~h}$.

cells, the chromatin became condensed and marginalized, the nuclear envelope appeared lytic and the cytoplasm was shrunken (Figure 2B). None of these features appeared in the untreated cells (Figure 2A). When treated with 80 and 160 $\mathrm{nmol} / \mathrm{L}$ triptolide for $24 \mathrm{~h}$, more apoptotic cells and cellular fragments could be seen (Figures 2C and 2D).

To determine if the triptolide-induced apoptosis was a concentration-dependent process, U266 cells were incubated with $0,40,80$ and $160 \mathrm{nmol} / \mathrm{L}$ triptolide for $24 \mathrm{~h}$ and analyzed by annexin V-FITC/PI staining and flow cytometry. The 40, 80 , and $160 \mathrm{nmol} / \mathrm{L}$ triptolide treatments resulted in apoptosis rates of $10.5 \% \pm 1.23 \%, 37.9 \% \pm 2.45 \%$, and $40.5 \% \pm 2.30 \%$, respectively, all of which were statistically different from the control $(3.8 \% \pm 1.98 \%$, Figure 3$)$.

The concentration-dependent apoptosis induced by triptolide was further analyzed by examining the caspase-3 activity of U266 cells by RT-PCR. When treated with triptolide $(40,80$, and $160 \mathrm{nmol} / \mathrm{L})$ for $24 \mathrm{~h}$, the mRNA expression of caspase-3 increased accordingly in a concentration-dependent manner, indicating that the caspase- 3 activity was upregulated by triptolide in U266 cells (Figure 4). Thus, caspase-induced apoptosis is the potential mechanism of triptolide-induced cell death.

\section{Location and expression of H3K9me1 in U266 cells with confocal microscopy}

A confocal microscope was used to visualize the subcellular location and expression of H3K9me1. H3K9me1 appeared with low fluorescence intensity in the nucleus, with the mean fluorescence density being $39.17 \pm 6.14$. The mean fluorescence density rose to $75.40 \pm 3.83(P<0.05)$ when U266 cells were cultured with $40 \mathrm{nmol} / \mathrm{L}$ triptolide for $24 \mathrm{~h}$ (Figure 5). Thus, triptolide increased the expression level of H3K9me1, although it still localized to the nucleus.
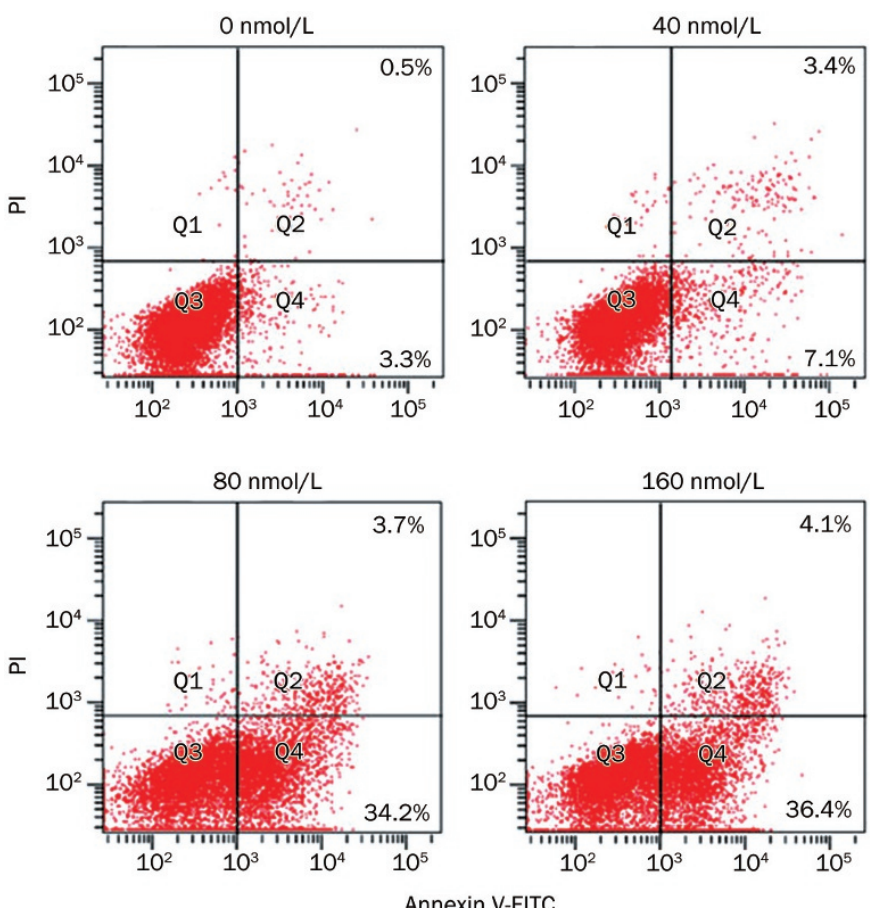

Figure 3. Striking triptolide-induced apoptotic death of U266 cells. Cells were treated with $0,40,80$, and $160 \mathrm{nmol} / \mathrm{L}$ triptolide for $24 \mathrm{~h}$. The induction of apoptosis was determined by Annexin V-FITC/PI double staining assay, and the degree of apoptotic cell death was quantified. Data represent the mean $\pm S D$ of at least three independent experiments.
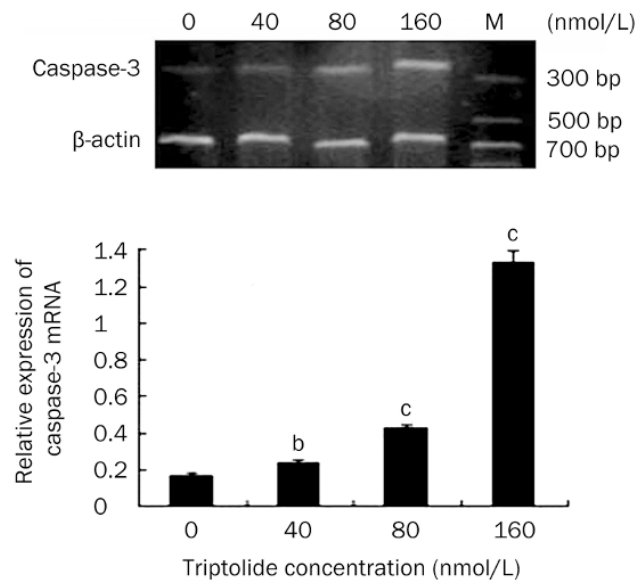

Figure 4. The mRNA expression of caspase-3 in U266 cells when treated by triptolide at different concentrations for $24 \mathrm{~h}$. Data represent the mean \pm SD of at least three independent experiments. ${ }^{b} P<0.05,{ }^{c} P<0.01$.

\section{Triptolide increased the protein expression of RIZ1 and H3K9me1 in U266 cells}

To investigate the protein expression of H3K9me1 and RIZ1 in U266 cells, Western blots were performed in at least three independent experiments. A comparison of RIZ1 protein expression in PBMC from healthy donors to that in U266 cells revealed that the levels of RIZ1 protein were dramati- 

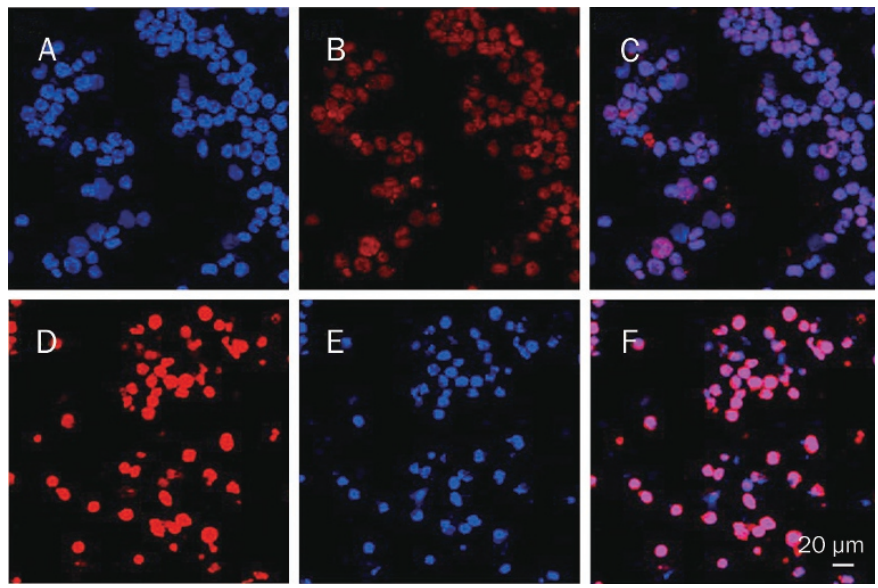

Figure 5. The effect of triptolide on the subcellular localization and expression of H3K9me1 in U266 cells $\times 400$. (A) Control, DNA stained with Hoechst 33258. (B) Control, H3K9me1 stained with TRITC. (C) Merged images from A and B. (D) Cells treated by triptolide, DNA stained with Hoechst 33258. (E) Cells treated by triptolide, H3K9me1 stained with TRITC. (F) Merged images from D and E.

cally decreased in the U266 cells (Figure 6A). In the U266 cells, treatment with triptolide at different concentrations for $48 \mathrm{~h}$ led to a significant increase in RIZ1 protein expression.
A

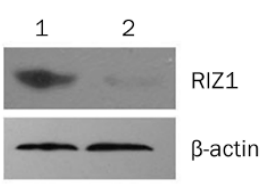

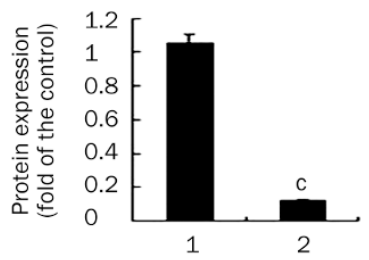

B
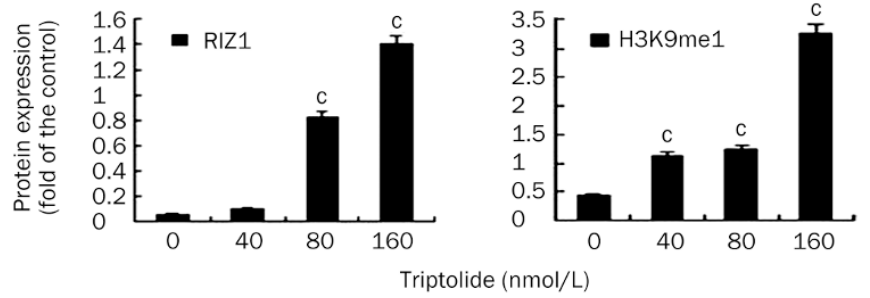

Figure 6. Protein expression of RIZ1 and H3K9me1, as detected by Western blotting. (A) Comparison of PBMC from healthy donors and U266 cells. Lane 1, protein expression of RIZ1 from PBMC; lane 2, protein expression from U266 cells. (B) Protein expression of RIZ1 and H3K9me1 in U266 cells after a 48-h treatment with triptolide at different concentrations. ${ }^{\mathrm{C}} P<0.01$.
Although the elevation was not significantly increased by the $40 \mathrm{nmol} / \mathrm{L}$ triptolide treatment, it was significantly increased by the 80 and $160 \mathrm{nmol} / \mathrm{L}$ treatments $(P<0.01$, Figure $6 \mathrm{~B})$. Accordingly, the protein expression of $\mathrm{H} 3 \mathrm{~K} 9 \mathrm{me} 1$ was upregulated dramatically in a concentration-dependent manner when U266 cells were treated with 40, 80, and $160 \mathrm{nmol} / \mathrm{L}$ triptolide (Figure 6B). The levels of RIZ1 in U266 cells were also analyzed by flow cytometry (Figure 7). In line with the Western blotting results, a 48 -h treatment with triptolide resulted in a significant increase in the MFI of fluorochrome-labeled U266 cells, which represented the level of RIZ1 protein expression, in a concentration-dependent manner.
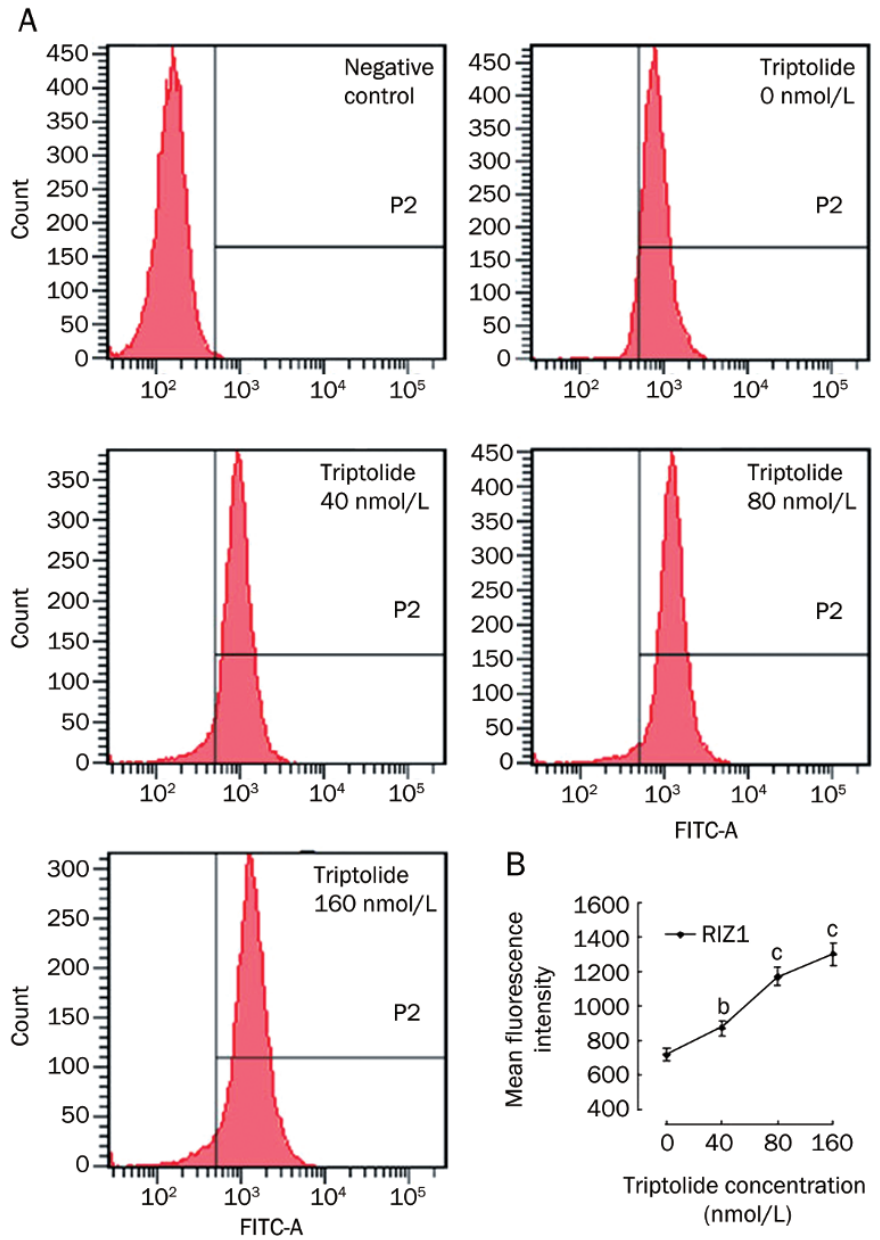

Figure 7. Examination of RIZ1 expression by flow cytometry. Mean fluorescence intensity was assessed over $48 \mathrm{~h}$ by FACS. (A) Cells treated with triptolide concentrations of $0,40,80$, and $160 \mathrm{nmol} / \mathrm{L}$ and their respective protein expression levels of RIZ1. (B) Histogram showing the MFI of FITC-labeled U266 cells. The figures are representative of at least three separate experiments. ${ }^{b} P<0.05,{ }^{C} P<0.01$.

Triptolide increased the mRNA expression of RIZ1 in U266 cells To determine if the increased RIZ1 protein levels were due to transcriptional regulation of the RIZ1 gene by triptolide, total RNA was extracted from triptolide-treated U266 cells and 
subjected to RT-PCR to detect the levels of RIZ1 mRNA. In accordance with the protein expression, the mRNA expression of riz1 was elevated dramatically after triptolide treatments of 40, 80, and $160 \mathrm{nmol} / \mathrm{L}$ for $24 \mathrm{~h}$ (Figure 8). These results suggest that triptolide increases the expression of RIZ1 at both the transcriptional and the translational level in a concentrationdependent manner.
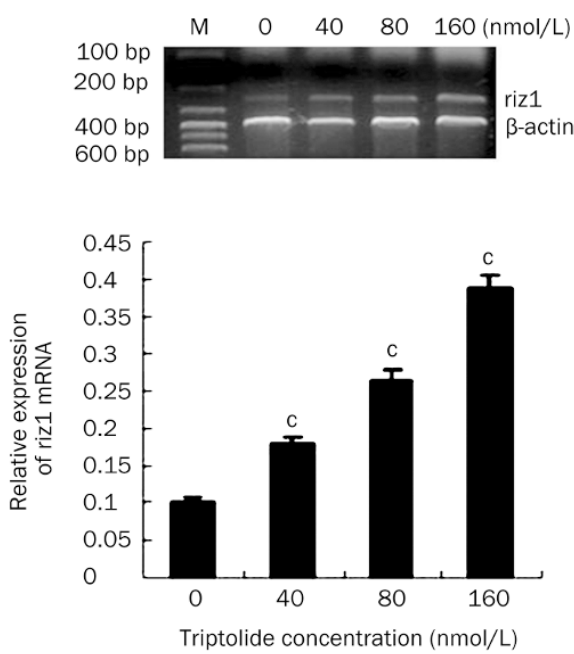

Figure 8. The mRNA expression of RIZ1 in U266 cells when treated by triptolide at different concentrations for $24 \mathrm{~h}$. Data represent the mean \pm SD of at least three independent experiments. ${ }^{c} P<0.01$.

\section{Discussion}

Multiple studies have suggested that triptolide possesses potent anti-tumor activity in hematologic malignancies, though the effects and mechanisms behind this activity are still not very clear. Multiple myeloma (MM) is a clonal B-cell neoplasm that accounts for $10 \%$ of all malignant hematologic neoplasms and that affects terminally differentiated B cells (eg, plasma cells). Recent studies have suggested that triptolide enhances PS-341-induced apoptosis via the PI3k/Akt/NF-kB pathways in human multiple myeloma cells ${ }^{[10]}$. In the present study, triptolide caused a striking concentration- and timedependent growth inhibition of U266 cells. A 24-h exposure resulted in an $\mathrm{IC}_{50}$ of $157.19 \pm 0.38 \mathrm{nmol} / \mathrm{L}$. Triptolide also exerted apoptosis-inducing activity. Triptolide treatment of U266 cells resulted in morphological changes typical of apoptosis; these changes included condensed and marginalized chromatin, lysis of the nuclear envelope and a shrunken cytoplasm. Flow cytometry demonstrated that triptolide could induce apoptosis in a concentration-dependent manner. As the triptolide concentration increased, the rate of apoptosis increased correspondingly. Triptolide has also been shown to induce apoptosis in other tumors, such as gastrointestinal malignancies and glioblastoma ${ }^{[17,18]}$. The anti-tumor mechanism of triptolide might be associated with the enhanced activity of $\mathrm{p} 21 \mathrm{waf1} / \operatorname{cip} 1^{[19]}$, the activation of caspases 8,9 , and $3^{[20]}$, degradation of the DNA repair enzyme PARP ${ }^{[21]}$, inhibition of the nuclear factor $\mathrm{\kappa B}(\mathrm{NF \kappa B})$ and upregulation of the nuclear factor $\kappa \mathrm{B}$ inhibiting protein $(\mathrm{I} \kappa \mathrm{Ba})^{[22]}$. Further research has indicated that apoptosis induced by triptolide in U266 cells is caspase 3 dependent, as caspase 3 mRNA levels increased subsequent to an increased concentration of triptolide. This observation suggests that the mechanism by which triptolide causes apoptosis in U266 cells is an increase in caspase 3 levels.

The RIZ1 protein contains a conserved positive regulatory (PR) domain that methylates histone $\mathrm{H} 3 \mathrm{~K} 9$ and is important for transcriptional repression. The intact PR domain is required for the tumor suppression function of RIZ1. Adenovirus-mediated RIZ1 expression causes $\mathrm{G}_{2}-\mathrm{M}$ cell cycle arrest and apoptosis in breast cancer, liver cancer, and colon cancer cells ${ }^{[23]}$. $\mathrm{RIZ1}^{-/-}$mice have a high incidence of diffuse large B-cell lymphoma and a broad spectrum of unusual tumors such as stomach squamous cell carcinoma, stomach polyp, fibrosarcoma, lung adenocarcinoma, pituitary tumor, lipoma, and hemangiosarcoma ${ }^{[24]}$. In CML patient samples, RIZ1 expression was decreased during the progression from the chronic phase to blast crisis. The induced expression of RIZ1 in CML blast crisis cell lines decreased proliferation, increased apoptosis, and enhanced differentiation ${ }^{[25]}$. The H3K9 methylation activity of RIZ1 may play a role in the epigenetic control of gene silencing. The decline in RIZ1 levels in tumor cells may be connected both with gene and histone hypermethylation. One of the potential carcinogenic molecular pathways has been suggested to involve the following steps, which then lead to the development of the cancer: 1) the inhibition and downregulation of RIZ1 in most cells of the target tissue; 2) the upregulation of pro-survival and pro-growth oncogenes such as c-Jun in most cells of the target tissue; 3) the stochastic accumulation of genetic and epigenetic changes in a single cell; 4) the clonal proliferation of that single cell; and 5) the differentiation of that cell into a tumor cell ${ }^{[26]}$.

Herein, the expression of RIZ1 in the multiple myeloma cell line U266 decreased significantly compared to that in healthy donors, a result seen in many other tumors. Triptolide treatment of U266 cells resulted in a striking elevation in the expression of RIZ1 at both the protein and the mRNA levels in a concentration- and time-dependent manner, suggesting that triptolide increases the expression of RIZ1 in U266 cells. Further study on histone H3K9 monomethylation (H3K9me1) elucidated that the expression of $\mathrm{H} 3 \mathrm{~K} 9 \mathrm{me} 1$ was upregulated in a concentration-dependent manner when the cells were treated with triptolide. Western blotting showed that the protein expression of H3K9me1 increased correspondingly with increasing concentrations of triptolide. Confocal microscopy indicated that $\mathrm{H} 3 \mathrm{~K} 9 \mathrm{me} 1$ localized to the nucleus, and concordantly with increasing triptolide concentrations, the expression of $\mathrm{H} 3 \mathrm{~K} 9 \mathrm{me} 1$ also increased. RIZ1 has methyltransferase activity towards histone $\mathrm{H} 3 \mathrm{~K}^{[27]}$, an activity known to be linked with transcriptional repression, and recent progress in understanding the effects of chromatin methylation on gene transcription suggests that silenced genes are associated with histone $\mathrm{H} 3 \mathrm{~K} 9$ methylation through transcriptional repression. 
Derepression and removal of histone H3K9 methylation can lead to a transcription-competent chromatin state. The methylation of H3K9 may also preclude activation-associated histone modifications, such as acetylation ${ }^{[28]}$, and disruption of the DNA binding of H3K9 methyltransferases: these modifications may be necessary for the derepression of silenced genes ${ }^{[13]}$. Recruitment of RIZ1 is an important step in the repression of gene transcription through its ability to upregulate histone $\mathrm{H} 3 \mathrm{~K} 9$, and hematological malignancies such as multiple myeloma might be caused by a perturbation of this process. By increasing the expression of histone $\mathrm{H} 3 \mathrm{~K} 9 \mathrm{me} 1$ through RIZ1 upregulation, triptolide may repress gene transcription, a potential mechanism against myeloma.

In summary, triptolide exerted proliferation-inhibitory and caspase-dependent apoptosis-inducing potencies in U266 cells in vitro. This study provided the evidence that the low expression levels of RIZ1 in the multiple myeloma cell line U266, which may be one of the steps triggering the development of cancer, could be reversed by treatment with triptolide and that the triptolide-induced increase in the expression of RIZ1 elevates the levels of histone H3K9me1. Therefore, the antimyeloma mechanism of triptolide may involve these downstream events.

\section{Acknowledgements}

This work was supported by a grant from the National Natural Sciences Foundation of China (No 30700882). The authors would like to thank the Department of Central Laboratory, Union Hospital, Tongji Medical College, Huazhong University of Science and Technology, Wuhan, China, for offering relevant experimental facilities and technical support.

\section{Author contribution}

Yan CHEN and Chun ZHANG designed the research; Fei ZHAO, Rui LI, Ling-lan ZENG, and Yuan LIU performed the research; Lu WEN and Rong ZENG analyzed the data; Fei $\mathrm{ZHAO}$ wrote the paper.

\section{References}

1 Kuehl WM, Bergsagel PL. Multiple myeloma: evolving genetic events and host interactions. Nat Rev Cancer 2002; 2: 175-87.

2 Alexanian R, Barlogie B, Tucker S. VAD-based regimens as primary treatment for multiple myeloma. Am J Hematol 1990; 33: 86-9.

3 Mitsiades CS, Mitsiades NS, Richardson PG, Munshi NC, Anderson KC. Multiple myeloma: a prototypic disease model for the characterization and therapeutic targeting of interactions between tumor cells and their local microenvironment. J Cell Biochem 2007; 101: 950-68.

4 Kiviharju TM, Lecane PS, Sellers RG, Peehl DM. Antiproliferative and proapoptotic activities of triptolide (PG490), a natural product entering clinical trials, on primary cultures of human prostatic epithelial cells. Clin Cancer Res 2002; 8: 2666-74.

5 Xiang M, Zhang CL. Advances in studies on immunosuppression of Tripterygium wilfordii. Chin Tradit Herbal Drugs 2005; 36: 458-61.

6 Yang S, Chen J, Guo Z, Xu XM, Wang L, Pei XF, et al. Triptolide inhibits the growth and metastasis of solid tumors. Mol Cancer Ther 2003; 2 : 65-72.

7 Carter BZ, Mak DH, Schober WD, Dietrich MF, Pinilla C, Vassilev LT, et al. Triptolide sensitizes AML cells to TRAIL-induced apoptosis via decrease of XIAP and p53-mediated increase of DR5. Blood 2008; 111: 3742-50.

8 Zhang C, Cui GH, Liu F, Wu QL, Chen Y. Inhibitory effect of triptolide on lymph node metastasis in patients with non-Hodgkin lymphoma by regulating SDF-1/CXCR4 axis in vitro. Acta Pharmacol Sin 2006; 27: 1438-46.

9 Carter BZ, Mak DH, Schober WD, McQueen T, Harris D, Estrov Z, et al. Triptolide induces caspase-dependent cell death mediated via the mitochondrial pathway in leukemic cells. Blood 2006; 108: 630-7.

10 Yang M, Huang J, Pan HZ, Jin J. Triptolide overcomes dexamethasone resistance and enhanced PS-341-induced apoptosis via PI3k/Akt/NFKB pathways in human multiple myeloma cells. Int J Mol Med 2008; 22: 489-96.

11 Sun W, Geyer CR, Yang J. Cloning, expression, purification and crystallization of the PR domain of human retinoblastoma protein-binding Zinc finger protein 1 (RIZ1). Int J Mol Sci 2008; 9: 943-50.

12 Gazzerro P, Abbondanza C, D’Arcangelo A, Rossi M, Medici N, Moncharmont $\mathrm{B}$, et al. Modulation of RIZ gene expression is associated to estradiol control of MCF-7 breast cancer cell proliferation. Exp Cell Res 2006; 312: 340-9.

13 Carling T, Kim KC, Yang XH, Gu J, Zhang XK, Huang S. A histone methyltransferase is required for maximal response to female sex hormones. Mol Cell Biol 2004; 24: 7032-42.

14 Nomoto S, Kinoshita T, Kato K, Otani S, Kasuya H, Takeda S, et al. Hypermethylation of multiple genes as clonal markers in multicentric hepatocellular carcinoma. Br J Cancer 2007; 97: 1260-5.

15 He L, Yu JX, Liu L, Buyse IM, Wang MS, Yang QC, et al. RIZ1, but not the alternative RIZ2 product of the same gene, is underexpressed in breast cancer, and forced RIZ1 expression causes $\mathrm{G}_{2}-\mathrm{M}$ cell cycle arrest and/or apoptosis. Cancer Res 1998; 58: 4238-44.

16 Pastural E, Takahashi N, Dong WF, Bainbridge M, Hull A, Pearson D, et al. RIZ1 repression is associated with insulin-like growth factor-1 signaling activation in chronic myeloid leukemia cell lines. Oncogene 2007; 26: 1586-94.

17 Zhou GX, Ding XL, Huang JF, Zhang H, Wu SB, Cheng JP, et al. Apoptosis of human pancreatic cancer cells induced by Triptolide. World J Gastroenterol 2008; 14: 1504-9.

18 Lin J, Chen LY, Lin ZX, Zhao ML. The effect of triptolide on apoptosis of glioblastoma multiforme (GBM) cells. J Int Med Res 2007; 35: $637-43$

19 Lavelle D, Chen YH, Hankewych M, DeSimone J. Histone deacetylase inhibitors increase p21 (WAF1) and induce apoptosis of human myeloma cell lines independent of decreased IL-6 receptor expression. Am J Hematol 2001; 68: 170-8.

20 Choi YJ, Kim TG, Kim YH, Lee SH, Kwon YK, Suh SI, et al. Immunosuppressant PG490 (triptolide) induces apoptosis through the activation of caspase-3 and down-regulation of XIAP in U937 cells. Biochem Pharmacol 2003; 66: 273-80.

21 Balasubramanian S, Ramos J, Luo W, Sirisawad M, Verner E, Buggy JJ. A novel histone deacetylase 8 (HDAC8)-specific inhibitor PCl-34051 induces apoptosis in T-cell lymphomas. Leukemia 2008; 22: 1026 34.

22 Yinjun L, Jie J, Yungui W. Triptolide inhibits transcription factor NFkappaB and induces apoptosis of multiple myeloma cells. Leuk Res 2005; 29: 99-105.

23 Lakshmikuttyamma A, Takahashi N, Pastural E, Torlakovic E, Amin HM, Garcia-Manero G, et al. RIZ1 is potential CML tumor suppressor that is down-regulated during disease progression. J Hematol Oncol 2009; 14; 2: 28.

24 Steele-Perkins G, Fang W, Yang XH, Van Gele M, Carling T, Gu J, et al. 
Tumor formation and inactivation of RIZ1, an Rb-binding member of a nuclear protein-methyltransferase superfamily. Genes Dev 2001; 15: 2250-62.

25 Piao GH, Piao WH, He Y, Zhang HH, Wang GQ, Piao Z. Hypermethylation of RIZ1 tumor suppressor gene is involved in the early tumorigenesis of hepatocellular carcinoma. Histol Histopathol 2008; 23: $1171-5$.

26 Zhou W, Alonso S, Takai D, Lu SC, Yamamoto F, Perucho M, et al.
Requirement of RIZ1 for cancer prevention by methyl-balanced diet. PLoS One 2008; 3: e3390.

27 Kim KC, Geng L, Huang S. Inactivation of a histone methyltransferase by mutations in human cancers. Cancer Res 2003; 63: 7619-23.

28 Wang H, Cao R, Xia L, Erdjument-Bromage H, Borchers C, Tempst P, et al. Purification and functional characterization of a histone H3-lysine 4-specific methyltransferase. Mol Cell 2001; 8: 1207-17.

\title{
26th International Pediatric Association Congress of Pediatrics (IPA 2010)
}

\author{
Johannesburg, South Africa \\ 5 to 9 August 2010
}

Website: http://www.kenes.com/ipa

Contact name: Liraz Bregman 